\title{
Analysis and study of 3D printing speed and molding room temperature on mechanical properties of PCB epoxy resin substrate
}

\author{
Wei Song \\ Electromechanical Engineering College \\ Guilin University of Electronic Technology \\ Guangxi, China \\ lelelinghu@qq.com
}

\author{
Dejian Zhou \\ Electromechanical Engineering College \\ Guilin University of Electronic Technology \\ Guangxi, China \\ emezdj@guet.edu.cn
}

\begin{abstract}
Based on the technological characteristics of the 3D printing, powder material through solid melt state - solid two phase transition, so printing process parameters will of molding stress distribution has a significant impact, thereby affecting the mechanical properties of the products. In particular, the 3D printing technology is applied to the manufacture of printed circuit boards (PCB), and it is needed to improve the mechanical properties of PCB by strictly controlling the warping deformation. Based on the selective laser sintering process, the paper has carried out the mechanical simulation of the FR-4 epoxy resin substrate printing process on the basis of PCB. The printing speed and the temperature of molding chamber on an FR-4 epoxy substrate equivalent stress distribution and warping effects. The results of the study show that: the maximum equivalent stress generally appears in the corners and edges model. Influence of printing speed on the equivalent stress is obvious. In the range of the actual printing speed, the maximum equivalent stress value of the printing piece shows a decreasing trend with the increasing of the printing speed and the temperature of the forming chamber, and the stress fluctuation range decreases gradually. In order to minimize the distortion of the printing piece, combining with the existing process conditions, the printing speed should be greater than $60 \mathrm{~mm} / \mathrm{s}$, the molding room temperature should not be less than 120 degrees Celsius. In this paper, the design of the related process parameters is proposed, which is helpful to improve the mechanical properties of the printing piece.
\end{abstract}

Keywords-3D printing technology; process parameters; $\mathrm{PCB}$ epoxy resin substrate; mechanical properties

\section{INTRODUCTION}

3D printing technology to its manufacturing process, manufacturing process, the advantages of a variety of complex structure, is gradually leading the new revolution in the manufacturing industry[1]. And in PC manufacturing production can greatly play to its unique advantages, the LDS (Laser Direct Structuring) process, inkjet printing technology as the representative of the new process, in a single, small batch and complex structure of PCB manufacturing in has achieved initial success. Especially in the current threedimensional assembly, high density assembly by using rapid development period, of PCB structures is presented in this paper, the high requirements of function. Using 3D printing technology to achieve production of printed circuit board can to a greater extent to play their respective advantages. Electronics assembly technology has gone through inserting technology to surface mount technology development, the progress of the technology but also to PCB surface smooth degree put forward more strict requirements, how to effectively control the PCB warpage is concerned problem [2]. Although 3D printing technology can produce high quality prints, but how to reduce the residual stress in the manufacturing process is still an important research topic. The residual stress of the assembly directly leads to the printing plate warping degree exceeding the limit. In the selective laser sintering process, the printing speed and the temperature of the molding room have a great influence on the residual stress, thus affecting the qualified rate of the products. In this paper, by using the finite element software to establish 3D PCB epoxy resin substrate based on $3 \mathrm{D}$ printing technology to manufacture and to the laser sintering process simulation of the component in the sintering process should force distribution and variation of the, effects of the printing speed and the molding chamber temperature equivalence force effect.

\section{INTRODUCTION OF SELECTIVE LASER SINTERING PROCESS}

Selective laser sintering (SLS) is the powdered material spreading on the supporting platform, and scraping or with a stick to grind flat, and then use the power of the laser scanning just paved the material powder in a specific section. Powder material in high intensity laser sintering together. Thus we have the print section, when after the completion of a layer of cross section of sintering, covered with a new layer of powder, repeat the above step scanning a section and with the following has formed part of the bond, resulting in a new layer of interface. Selective laser sintering process, as shown in Figure 1.

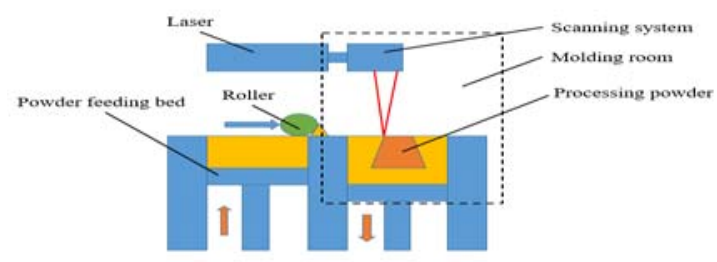

Fig. 1. Selective laser sintering process 


\section{ESTABLISHMENT SIMULATION MODEL}

The PCB substrate sample model using FR4 epoxy resin material production, in order to facilitate the research, the model was simplified, ignoring the print head temperature, angle of print, print track and other factors influence, also in order to save computing time, Standard Specification for substrate size shrink selected sample size of $20 \times 20 \times 1.2 \mathrm{~mm}$, and mesh according to the actual printing process, the partition model as the $1 \times 1 \times 0.3 \mathrm{~mm}$ cuboid, a total of 1600 units. In the simulation process of print, one by one the activation of each unit, in accordance with the hierarchical relation layer by layer print. Overall geometric model as shown in Figure 2.

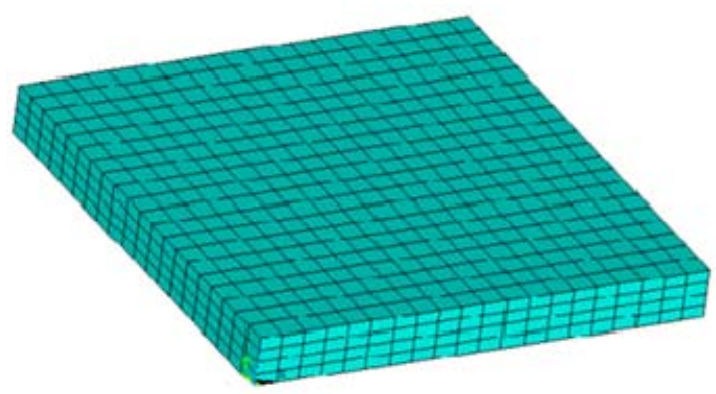

Fig. 2. Global geometric model

The print material properties are shown in Table 1.

TABLE I. MATERIAL PROPERTIES

\begin{tabular}{|c|c|c|c|c|}
\hline $\begin{array}{c}\text { Material } \\
\text { model }\end{array}$ & $\begin{array}{l}\text { Mechanical } \\
\text { properties }\end{array}$ & $\begin{array}{c}\text { Electrical } \\
\text { characteristics }\end{array}$ & $\begin{array}{c}\text { Melting point } \\
\text { / Thermal } \\
\text { characteristics }\end{array}$ & $\begin{array}{l}\text { Application } \\
\text { range }\end{array}$ \\
\hline FR4 & $\begin{array}{c}\text { Vertical } \\
\text { bending } \\
\text { strength: } \\
\text { 150MPa; } \\
\text { parallel } \\
\text { direction } \\
\text { impact } \\
\text { strength } \\
230 \mathrm{KJ} / \mathrm{m} \text {. }\end{array}$ & $\begin{array}{c}\text { Insulation } \\
\text { resistance: } \\
500 \mathrm{M} ; \\
\text { dielectric } \\
\text { constant: 5.5. }\end{array}$ & $\begin{array}{c}\text { Melting } \\
\text { point: } 203 \\
\text { degrees C / } \\
\text { thermal } \\
\text { expansion } \\
\text { coefficient: } \\
\text { 16,16145/240 } \\
(\mathrm{X}, \mathrm{Y}, \mathrm{Z})\end{array}$ & $\begin{array}{l}\text { Suitable for } \\
1 \mathrm{GHz} \\
\text { below the } \\
\text { microwave } \\
\text { circuit and } \\
3 \mathrm{GHz} \\
\text { below the } \\
\text { digital } \\
\text { circuit } \\
\text { board. }\end{array}$ \\
\hline
\end{tabular}

In the process of 3D printing, the finite element analysis of temperature field is a nonlinear transient thermal analysis, and the differential equation of transient temperature field in rectangular coordinate system is as follows:

$$
\rho c \frac{\partial \Theta}{\partial t}-\frac{\partial}{\partial x}\left(K_{x} \frac{\partial \Theta}{\partial x}\right)-\frac{\partial}{\partial y}\left(K_{y} \frac{\partial \Theta}{\partial y}\right)-\frac{\partial}{\partial z}\left(K_{z} \frac{\partial \Theta}{\partial z}\right)-\rho Q=0
$$

In the Formula, $\rho$-Material density $(\mathrm{Kg} / \mathrm{m} 3)$;

$$
\begin{aligned}
& \text { c-Material specific heat, }\left(\mathrm{J} / \mathrm{Kg} \bullet{ }^{\circ} \mathrm{C}\right) \\
& \text { t-time, (s) ; }
\end{aligned}
$$

$\mathrm{K}_{\mathrm{x}}, \mathrm{K}_{\mathrm{y}}, \mathrm{K}_{\mathrm{z}}-$ Material along $\mathrm{X}, \mathrm{y}, \mathrm{z}$ rection of the heat transfer coefficient $\left(\mathrm{W} / \mathrm{m} \bullet{ }^{\circ} \mathrm{C}\right)$;

$\mathrm{Q}=\mathrm{Q} \quad(\mathrm{x}, \mathrm{y}, \mathrm{z}, \mathrm{t})$-Heat source density within an object (W/Kg);

The physical meaning of the equation is: micro heating required heat equal to external inflows micro heat and micro heat source heat and. In order to make the heat balance equation of each node is the only solution that you need to add a certain initial and boundary condition. In order to simulate the process of laser sintering, the mobile applied laser heat source to choose reasonable heat source model, the combined with the process parameters of the printing process, print setting temperature of 350 DEG C. According to the domestic and foreign research experience and the literature record, this paper uses Gauss heat source model. Each unit mainly consider the heat input power, heat radiation, heat convection and heat conduction effects.

In analog printing processes, with material unit continuously activates the heat source and the boundary conditions are imposed, then solving the temperature field. Not activated unit quite to be "killed" state. Do is in order to consider increasing material process of printing part of the effect.

\section{THE ANALYSIS OF SIMULATION RESULTS}

\section{Effect of printing speed on equivalent stress of PCB plate}

In the simulation process of 3D printing, by looking up the literature to determine the basic parameters of [4], and then selected molding temperature of 150 DEG C, simulations are performed in different print speeds $(20 \mathrm{~mm} / \mathrm{s} \sim 100 \mathrm{~mm} / \mathrm{s})$ and in print at the time of the end of print parts of the stress field distribution were analyzed. Due to the uneven distribution of temperature in the printing process, the printout model exhibited equivalent stress distribution is not uniform. In the printing speed $20 \mathrm{~mm} / \mathrm{s}$, at the end of the print principal stress stress diagram as shown in Figure 3 . When the print speed is $80 \mathrm{~mm} / \mathrm{s}$, stress diagram as shown in Figure 4.

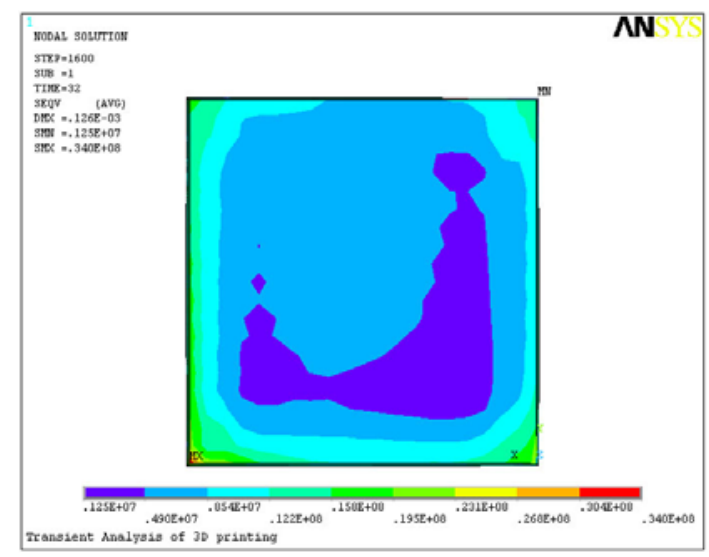

Fig. 3. $\quad \mathrm{V}=20 \mathrm{~mm} / \mathrm{sPrincipal}$ stress contour 


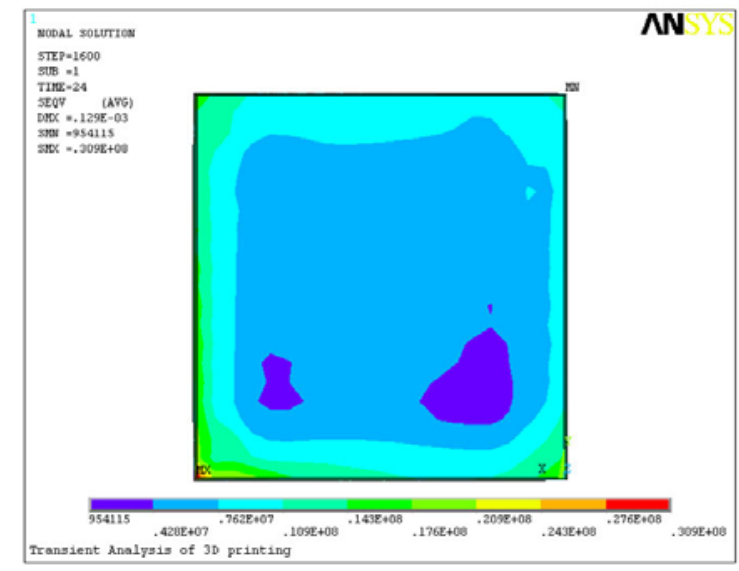

Fig. 4. $\quad \mathrm{V}=80 \mathrm{~mm} / \mathrm{sPrincipal}$ stress contour

Compared the above chart shows, typing principal stress increase gradually from the center to the periphery. The maximum stress values appeared at the corner of the model, and tensile force, which is at the corner of the deformation of the reasons for the larger. When the print speed increases, the stress relatively more uniform distribution, a printout of the overall stress values decreased significantly. According to the simulation results, different print speed, print the maximum equivalent stress value as shown in Table 2:

TABLE II. THE RELATIONSHIP BETWEEN THE PRINTING SPEED AND THE MAXIMUM EQUIVALENT STRESS

\begin{tabular}{|c|c|c|c|c|c|}
\hline Print speedV(mm/s) & 20 & 40 & 60 & 80 & 100 \\
\hline $\begin{array}{c}\text { Maximum } \\
\text { equivalent stress } \sigma \\
(\mathrm{MPa})\end{array}$ & 61.58 & 56.42 & 48.26 & 27.44 & 16.89 \\
\hline
\end{tabular}

According to the table 2 data, draw the scatter diagram as shown in figure 5:

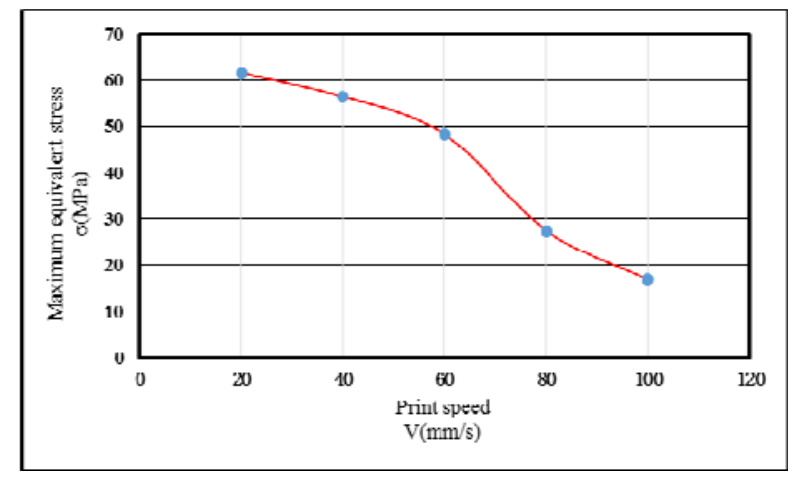

Fig. 5. The relationship between the printing speed and the maximum equivalent stress

The simulation result shows that the maximum equivalent stress generally appear in the model edge corner. We can see from Figure 5, affect the printing speed of the equivalent stress is obvious. In the actual print speed range, the maximum equivalent stress value with increasing printing speed decreased. This is because in the process of printing materials experience from solid to liquid, and then into a solid process, will produce stress relaxation distribution is relatively uniform and the peak [5]. Because of the stress function, print the overall deformation tendency of four angle shrink to the center. When the printing speed, improve the overall temperature model at the end of the printing, between each part model of temperature decreases, the stress distribution is more uniform, in order to make the print warpage degree with narrow as far as possible, the existing technical conditions, the printing speed should be greater than $60 \mathrm{~mm} / \mathrm{s}$.

\section{Effect of room temperature on the equivalent stress of PCB substrate during printing}

To the influence of different molding chamber temperature equivalent stress, under the premise of the other parameters are fixed, the fixed printing speed is $70 \mathrm{~mm} / \mathrm{s}$, under the different molding room temperature (100 DEG C to 150 DEG C) simulation, when the molding chamber temperature of 110 DEG $\mathrm{C}$, to obtain the equivalent should stress diagram as shown in Figure 6, the molding chamber temperature is 130 DEG C, to obtain the equivalent should stress diagram as shown in Figure 7.

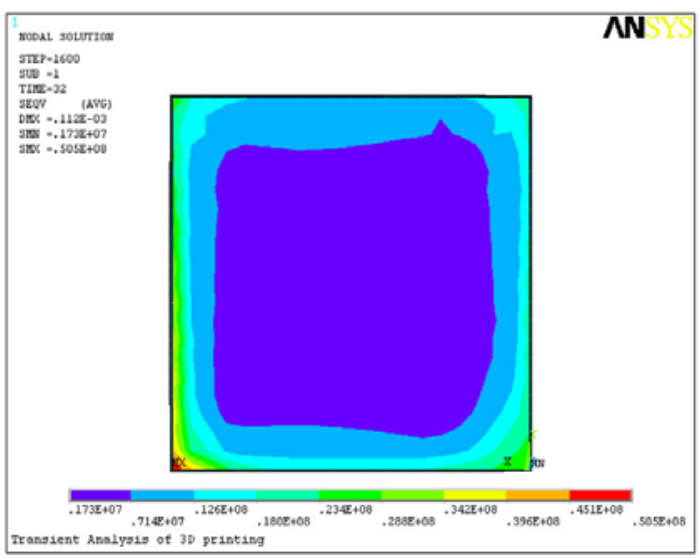

Fig. 6. $\quad \mathrm{T}=110^{\circ} \mathrm{C}$ Principal stress contour

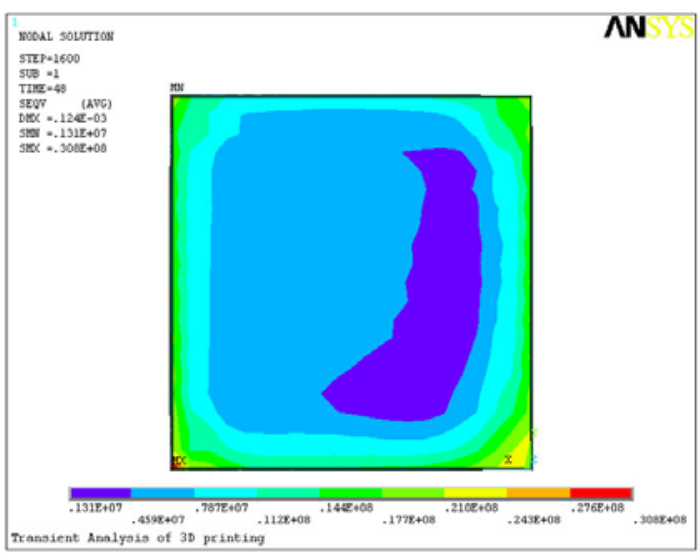

Fig. 7. $\quad \mathrm{T}=130^{\circ} \mathrm{C}$ Principal stress contour

Headings, or heads, are organizational devices that guide the reader through your paper. There are two types: component heads and text heads.

The comparison shows that when the temperature of the forming chamber is increased, the maximum stress of the printing piece is reduced. According to the simulation results, 
the maximum equivalent stress value of the printer is shown in Table 3:

TABLE III. THE RELATIONSHIP BETWEEN THE PRINTING SPEED AND THE MAXIMUM EQUIVALENT STRESS

\begin{tabular}{|c|c|c|c|c|c|c|}
\hline $\begin{array}{c}\text { Molding room } \\
\text { temperatureT }\left({ }^{\circ} \mathrm{C}\right)\end{array}$ & 100 & 110 & 120 & 130 & 140 & 150 \\
\hline $\begin{array}{c}\text { Maximum } \\
\text { equivalent stress } \\
\sigma(\mathrm{MPa})\end{array}$ & 46.58 & 44.69 & 38.46 & 36.24 & 34.75 & 33.19 \\
\hline
\end{tabular}

According to the table 3 data, draw the scatter diagram as shown in figure 8:

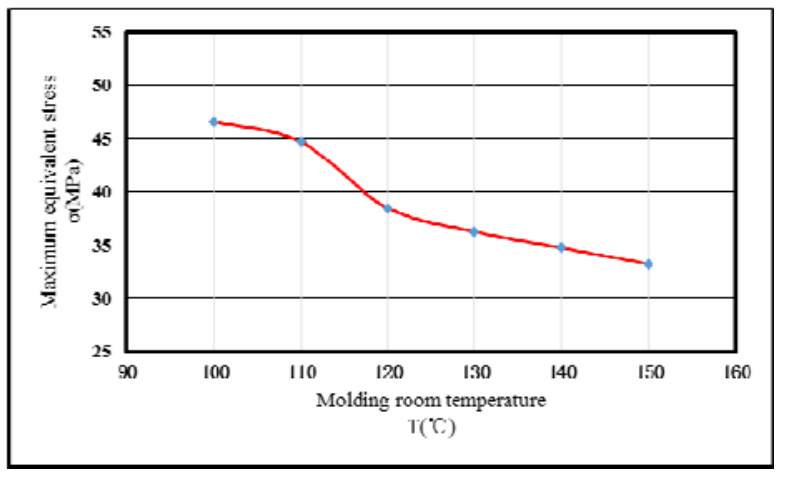

Fig. 8. Relationship between temperature and maximum equivalent stress

A printout of the maximum equivalent stress value presented a decreasing trend with increasing the temperature of the molding chamber, and the stress amplitude decreases. According to the literature should be force fluctuations if the larger sample print stress is not uniform, more prone to warping deformation. So to reduce the force fluctuation in high print quality, reduce the warp distortion has important significance. Combined with the existing process conditions, temperature of molding chamber should be not less than $120^{\circ} \mathrm{C}$.

\section{CONCLUSIONS}

In this paper, as the preliminary research work of 3D printing PCB technology, based on the selective laser sintering process, the printing process of the PCB substrate is simulated. The influence of printing speed and temperature on the equivalent stress distribution of FR-4 epoxy resin PCB was studied, and the result was analyzed, and the following conclusions were obtained:
1) The maximum equivalent stress occurred in the corner edge of the model. The influence of printing speed equivalent stress is obvious. Within the range of the actual print speed, print the maximum equivalent stress values tend to decrease with increasing the speed of printing. In order to minimize the distortion of the printing piece, combined with the existing process conditions, the printing speed should be greater than 60 $\mathrm{mm} / \mathrm{s}$.

2) The maximum equivalent stress value of the printing piece is decreased with the increase of the temperature of the molding chamber, and the stress fluctuation range decreases. In order to minimize the warping deformation of the printing piece, combined with the existing process conditions, the molding room temperature should not be less than $120{ }^{\circ} \mathrm{C}$.

\section{References}

[1] Ambrosi A, Pumera M. 3D-printing technologies for electrochemical applications[J]. Chemical Society Reviews, 2016.J. Clerk Maxwell, A Treatise on Electricity and Magnetism, 3rd ed., vol. 2. Oxford: Clarendon, 1892, pp.68-73.

[2] Yule Gao,Changchun Shi,Dechao Dong, et al. Research on Rapid Prototyping Technology of flexible electronic circuits based on 3D printing technology [J]. printed circuit information, 2016, 24 (3): 5-8.Y. Yorozu, M. Hirano, K. Oka, and Y. Tagawa, "Electron spectroscopy studies on magneto-optical media and plastic substrate interface,” IEEE Transl. J. Magn. Japan, vol. 2, pp. 740-741, August 1987 [Digests 9th Annual Conf. Magnetics Japan, p. 301, 1982].

[3] Long Zhang. Study on computer simulation of 3D printing process [D]. Lanzhou University of Technology, 2014.

[4] Naifei Ren, Yan Zhao. Effect of selective laser sintering parameters on the properties of sintered parts 316L Electronic Science and technology, 2016, 29 (1): 1-4.

[5] Zefeng Xiao, Yongqiang Yang, Changhui Song, et al. Laser selective sintering process and properties of ultra high molecular weight polyethylene [J]. optical and precision engineering, 2016, 24 (3): 502510.

[6] Qiang Song, Qiuping Pan. The cause and solution of PCB burst [J]. printed circuit information, 2016, 24 (3): 34-37.

[7] O’Brien E K, Wayne D B, Barsness K A, et al. Use of 3D Printing for Medical Education Models in Transplantation Medicine: a Critical Review[J]. Current Transplantation Reports, 2016, 3(1): 109-119. 